\title{
The effect of exercise during pregnancy on gestational diabetes mellitus in normal- weight women: a systematic review and meta-analysis
}

Wai-Kit Ming ${ }^{1,2,3+}$, Wenjing Ding ${ }^{1 \dagger}$, Casper J. P. Zhang ${ }^{4}$, Liegiang Zhong ${ }^{1}$, Yuhang Long ${ }^{1}$, Zhuyu Li ${ }^{1}$, Cong Sun ${ }^{1}$, Yanxin $\mathrm{Wu}^{1}$, Hanqing Chen ${ }^{1}$, Haitian Chen ${ }^{1}$ and Zilian Wang ${ }^{1 *}$ (D)

\begin{abstract}
Background: Gestational diabetes mellitus (GDM) is one of the most common complications during pregnancy, and it has both short- and long-term adverse effects on the health of mothers and fetuses. To investigate the effect of exercise during pregnancy on the occurrence of GDM among normal-weight pregnant women.

Methods: We searched for studies published between January 1994 and June 2017 that appeared in the Web of Science, Scopus, ClinicalTrials.gov or Cochrane library databases. Randomized controlled trials that investigated the preventive effect of exercise on GDM in normal-weight women were included. Interventions including any confounding factors (e.g., dietary) were excluded. We extracted maternal characteristics, the diagnostic criteria of GDM, and basic information for intervention and obstetric outcomes. The primary outcome was the occurrence of GDM, and the secondary outcomes included gestational weight gain, gestational age at birth, birth weight, and the odds of cesarean section. A meta-analysis was conducted based on calculations of pooled estimates using the random-effects model.

Results: Eight studies were included in this systematic review and meta-analysis. Exercise during pregnancy was shown to decrease the occurrence of $\mathrm{GDM}[\mathrm{RR}=0.58,95 \% \mathrm{Cl}(0.37,0.90), P=0.01$ and $\mathrm{RR}=0.60,95 \% \mathrm{Cl}(0.36,0.98)$, $P=0.04$ based on different diagnosis criteria, respectively] in normal-weight women. Regarding secondary outcomes, exercise during pregnancy can decrease gestational weight gain $[M D=-1.61,95 \% \mathrm{Cl}(-1.99,-1.22)$, $P<0.01]$, and had no significant effects on gestational age at birth $[\mathrm{MD}=-0.55,95 \% \mathrm{Cl}(-1.57,0.47), P=0.29]$, birth weight $[\mathrm{MD}=-18.70,95 \% \mathrm{Cl}(-52.49,15.08), P=0.28]$, and the odds of caesarean section $[\mathrm{RR}=0.88,95 \% \mathrm{Cl}$ $(0.72,1.08), P=0.21]$, respectively.
\end{abstract}

Conclusions: Exercise during pregnancy can ostensibly decrease the occurrence of GDM without reducing gestational age at delivery and increasing the odds of cesarean section in normal-weight women.

Keywords: Exercise, Gestational diabetes mellitus, Systematic review, Meta-analysis

\footnotetext{
* Correspondence: wangzil@mail.sysu.edu.cn

+Wai-Kit Ming and Wenjing Ding contributed equally to this work.

${ }^{1}$ Department of Obstetrics and Gynaecology, The First Affiliated Hospital of

Sun Yat-sen University, Guangzhou, China

Full list of author information is available at the end of the article
}

(C) The Author(s). 2018 Open Access This article is distributed under the terms of the Creative Commons Attribution 4.0 International License (http://creativecommons.org/licenses/by/4.0/), which permits unrestricted use, distribution, and reproduction in any medium, provided you give appropriate credit to the original author(s) and the source, provide a link to the Creative Commons license, and indicate if changes were made. The Creative Commons Public Domain Dedication waiver (http://creativecommons.org/publicdomain/zero/1.0/) applies to the data made available in this article, unless otherwise stated. 


\section{Background}

Gestational diabetes mellitus (GDM) is a common complication of pregnancy; based on the diagnosis criteria published by the International Association of Diabetes and Pregnancy Study Groups (IADPSG), the estimated prevalence of GDM worldwide is $17.8 \%$ [1]. In 2013, the World Health Organization (WHO) adopted the IADPSG evidence-based criteria as their standard for GDM diagnosis [2, 3]; these criteria use lower thresholds for several indices (i.e., a fasting glucose $\geq 5.1 \mathrm{mmol} / \mathrm{l}$, or a one-hour result $\geq 10.0 \mathrm{mmol} / \mathrm{l}$, or a two-hour result $\geq 8.5 \mathrm{mmol} / \mathrm{l}$, using a $75 \mathrm{~g}$ oral glucose tolerance test) than previously accepted, therefore yielding more cases of GDM [4]. Gestational diabetes mellitus is more common among women who are overweight or of advanced maternal age, have a history of GDM and macrosomia, and who have a family history of diabetes [5-8].

Gestational diabetes mellitus can affect the health of mothers and their offspring due to transient abnormalities in carbohydrate metabolism $[1,5,9,10]$. Women with GDM are at higher risk of experiencing fetal demise, fetal malformation, preterm birth, macrosomia, polyhydramnios, infection, and cesarean section than the general population [11-15]. Furthermore, both women with GDM and their infants are more likely to become overweight or obese [16, 17] and develop type 2 diabetes mellitus (T2DM) [10], cardiovascular diseases (CVD) and neuropsychological deficits later in life than the normal group $[1,17,18]$.

Recent studies have demonstrated that GDM could be modified by lifestyle interventions such as exercise and diet control [19]. Exercise is characterized as planned, structured, repetitive movement that has a specific goal (e.g., health improvement). It is a subcategory of physical activity, which refers to any movement that involves energy expenditures and the use of skeletal muscles [20]. Exercise is deemed to be an important component of lifestyle intervention for GDM [21]. Regular exercise reduces the risk of T2DM, CVD, and metabolic syndrome in non-pregnant patients [22, 23]. The Royal College of Obstetricians and Gynecologists (RCOG) recommends that to accrue health benefits, healthy pregnant women should engage at least $30 \mathrm{~min}$ of moderate-intensity exercise at least four times per week [24]. However, only a small proportion of pregnant women achieve this goal.

Several meta-analyses support the evidence that exercise protects against GDM. Da Silva et al. concluded that leisure-time physical activity during pregnancy played a protective role against the development of GDM [25]; another meta-analysis of randomized controlled trials (RCTs) found that exercise prevents GDM in normal-weight and overweight women [26]; yet another meta-analysis of the association between exercise and preterm birth also showed that exercise lowers the occurrence of GDM in overweight or obese women [27].

\section{Objectives}

The majority of the GDM population comprises women of normal weights (based on pre-pregnant body mass index $[\mathrm{BMI}])$. However, the existing systematic reviews and meta-analyses focused on the over-weight or obese population [28]. Exclusively on the normal-weight population, there are few reviews of pregnancy outcomes and one recent paper focused on the exercise during pregnancy in the normal-weight population and the risk of preterm birth [29]. To our knowledge, no published reviews have examined GDM in such population. Evidence of how exercise influencing GDM in normal-weight women could inform first-line treatments of GDM in clinical practice. Earlier meta-analyses of all-weight populations did not rule out the impact of maternal weight on GDM given that overweight and obese populations are at high risk of GDM and their status may be attributed to a variety of factors. Here, we synthesized available evidence of RCTs of exercise during pregnancy in preventing GDM in normal-weight women.

\section{Methods}

We conducted a systematic review and meta-analysis and reported our findings according to the Preferred Reporting Items for Systematic Reviews and MetaAnalyses (PRISMA) statement.

\section{Search strategy}

We searched Web of Science, Scopus (including Pubmed, MEDLINE and Embase), ClinicalTrials.gov and the Cochrane Library for articles published between January 1994 and June 2017, using the following combinations of keywords: ('activit"' OR 'fitness' OR 'exercise' OR 'sport"' OR 'physical activit"' OR 'physical exercise') AND ('pregnancy' OR 'wom*') AND ('trial"') AND ('diabetes' OR 'gestational diabetes' OR 'gestational diabetes mellitus' OR 'GDM' OR 'glucose'). The integrated search strategy is shown in Additional file 1: Textbox 1. These search terms were reviewed by a trained librarian and a physician. Reference citations for relevant articles were additionally screened to identify possible missing publications.

\section{Study selection}

Studies were included if they satisfied the following conditions: 1) they consisted of randomized controlled trials; 2) interventions used in the study included at least one type of exercise; 3) the occurrence of GDM was reported for both the intervention and control groups; 4) subjects 
were pregnant women with a pre-pregnancy BMI or a mean pre-pregnancy BMI ranging from $18.5-24.9 \mathrm{~kg} /$ $\mathrm{m}^{2}$. Publications were excluded if they met any of the following conditions: 1) they integrated interventions of other factors (e.g., dietary) confounding the independent effects of exercise on the occurrence of GDM; 2) the pre-pregnancy BMI or the mean pre-pregnancy BMI of each group was less than $18.5 \mathrm{~kg} / \mathrm{m}^{2}$ or equal to or greater than $25 \mathrm{~kg} / \mathrm{m}^{2}$; 3) papers were literature reviews, case reports or protocols; 4 ) only the abstract or conference contents were published, or the studies lacked specific data.

\section{Data extraction and outcome measures}

Two reviewers (W.D., W.M.) independently searched the literature and extracted data from all eligible studies. Any discrepancy in crosschecks was resolved by a third reviewer and by discussion between all participating authors. The following data were extracted if available: 1) study characteristics (authors, publication year, country, affiliation of the authors, number of subjects, and gestational period); 2) exercise intervention (type, frequency, duration, and intensity); 3) pregnancy outcomes (GDM, gestational weight gain [GWG], caesarean section, gestational age, and birth weight). The primary outcome was the occurrence of GDM, and the secondary outcomes included gestational age at birth, cesarean section, birth weight, and GWG.

\section{Assessment of risk of Bias}

Quality assessment was based on the criteria outlined in the Cochrane Handbook for Systematic Reviews of Interventions and consisted of 1) randomization; 2) concealment of allocation; 3) blinding of the outcome assessment (blinding of participants and healthcare providers was impossible owing to the nature of exercise); 4) incomplete outcome data; 5) selective reporting and 6) other potential bias.

\section{Data synthesis}

Data analysis was conducted using Review Manager 5.3 (RevMan 5.3). Relative risks (RRs) or mean differences (MDs) with 95\% confidence intervals (CIs) were used to calculate pooled effects. Relative risks were reported for dichotomous outcomes (i.e., the occurrence of GDM and cesarean section), and MDs were reported for continuous outcomes (i.e., gestational age at birth, gestational weight gain, and birth weight). Heterogeneity was assessed using the Cochran $\mathrm{Q}$ statistic $(P<0.1)$, qualified with Higgins $\mathrm{I}^{2}$ statistics. A $p$-value less than 0.05 in the two-tailed tests was considered to be statistically significant.

\section{Results}

Study selection and characteristics

We identified 5077 publications in four databases. Upon screening the titles and abstracts, the full texts of 21 studies were reviewed. Of these studies, 13 were excluded due to the following reasons: the pre-pregnancy BMI of the patients did not meet the inclusion criteria (7 studies) [30-36], the patients underwent lifestyle interventions including dietary changes (3 studies) [37-39], there were no control groups (2 studies) [40, 41], or the studies were only observational (2 studies) [42, 43]. Eight RCTs [44-51], including a total of 3256 pregnant women, were eligible for this meta-analysis. The detailed selection procedure is shown in Fig. 1. The publication bias in the primary outcome was assessed by a funnel plot, and the results revealed that such bias existed (Fig. 2).

The general characteristics of the included RCTs are listed in Table 1. All trials were conducted in European countries. The sample sizes ranged from 83 to 962 . With the exception of Stafne et al. [50], all of the interventions adopted comprehensive exercise programs of light-tomoderate intensity that were performed three times per week. The duration of each exercise period ranged from 35 to $60 \mathrm{~min}$. Seven trials started in the first trimester and continued to the end of the third trimester [44-49, 51], and only one trial spanned the 20th through 36th weeks of gestation [50]. Pregnant women in the control group received regular antenatal care in all trials.

All studies reported the occurrence of GDM, gestational age at birth and birth weight; in addition, gestational weight gain was reported in five studies [45-47, 49, 51]; and the likelihood of caesarean section was reported in seven studies [44, 45, 47-51].

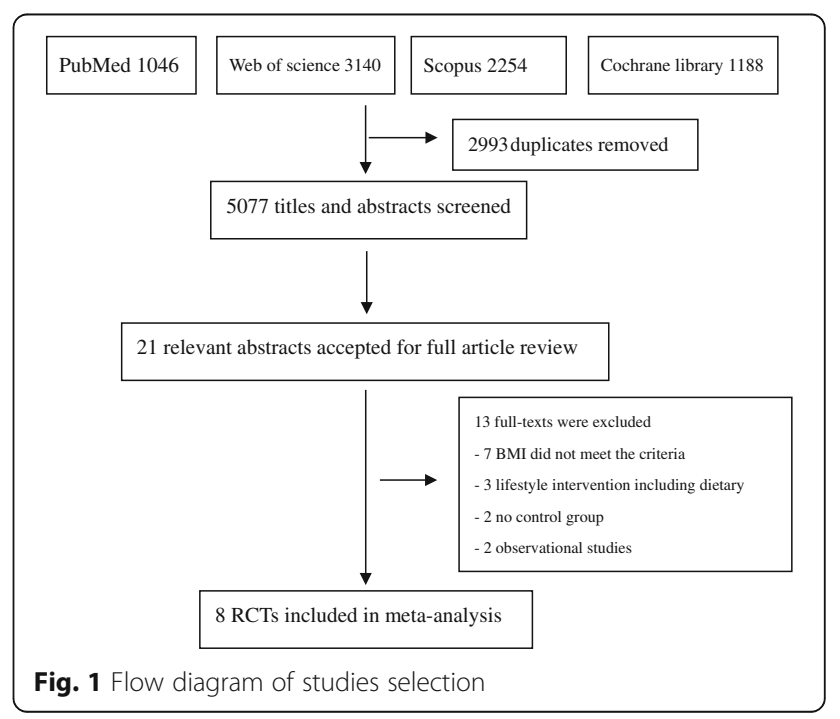




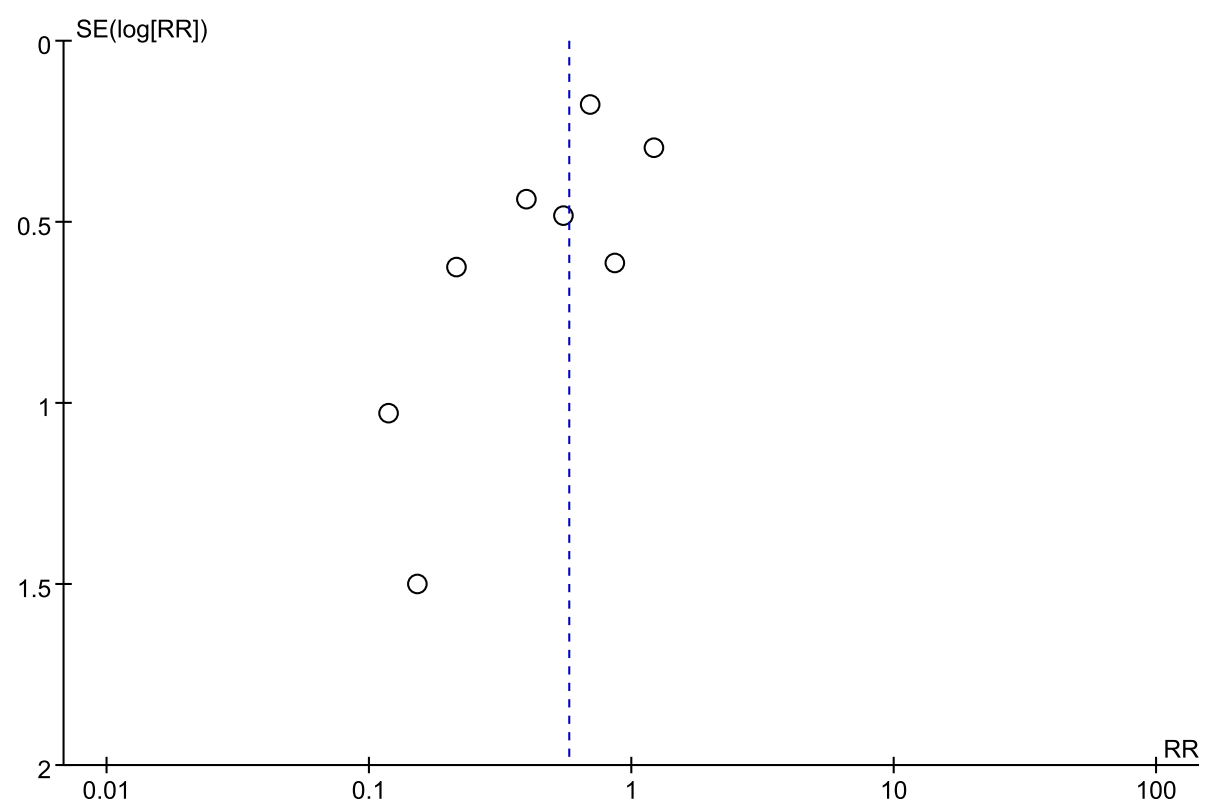

Fig. 2 Funnel plot for assessing publication bias SE: standard error; RR: relative risk

\section{Risk of Bias in the included studies}

Due to the nature of the exercise, blinding of personnel and participants was impractical. We accordingly excluded the blinding component from the bias assessment. Overall, the included trials displayed specific methodological bias (Fig. 3). Five trials showed a low risk of randomization based on the use of a computer random number generator $[45-47,50,51]$, and one trial showed a high risk of bias (i.e., randomization is based on the sequence of entering study) [48], and two trials did not report this aspect. Three trials reported that the group allocation was concealed from the staff who conducted the assessment $[45,50,51]$. In terms of incomplete outcome data, three trials reported a full description of participants and follow-up status during the trial [45, 50, 51]. Only one trial was associated with a low risk of selective reporting bias of its outcomes [44].

\section{Synthesis of results}

\section{Primary outcome: The occurrence of GDM}

The diagnostic criteria for GDM varied among the eight RCTs (among these eight studies, one of the RCT with two criteria, as a result, we decided to did additional analysis as two RCTs): two were based on WHO criteria $[50,51]$, one was based on IADPSG criteria [51], one was based on National Diabetes Data Group (NDDG) criteria [44], one was based on criteria defined by the authors (self-reported criteria) [49]; and four studies did not report their diagnostic criteria [45-48]. Notably, one trial determined the occurrence of GDM based on the WHO criteria (before 2013) as well as the IADPSG criteria [denoted as "Barakat(a) 2013" and "Barakat(b) 2013," respectively] (Table 1 ).

The analysis included 1472 women in the intervention group and 1509 women in the control group. Barakat et al. [51] was analyzed as two separate trials due to different diagnosis criteria used. Exercise during pregnancy significantly decreased the occurrence of GDM $[\mathrm{RR}=$ $0.58,95 \%$ CI $(0.37,0.90), P=0.01$ and $\mathrm{RR}=0.60,95 \% \mathrm{CI}$ (0.36, 0.98), $P=0.04$ based on different diagnosis criteria, respectively] in normal-weight women. The absolute risk reduction was $3.66 \%$ and $2.53 \%$, respectively. The heterogeneity across included studies was high $\left(\mathrm{I}^{2}=46 \%\right.$ and $52 \%, P=0.07$ and 0.04 ) (Figs. 4 and 5).

\section{Secondary outcomes}

Exercise had no significant impact on gestational weight gain $[\mathrm{MD}=-1.61,95 \% \mathrm{CI} \quad(-1.99, \quad-1.22), \quad P<0.01$; Additional file 2: Figure S1], gestational age at birth $[\mathrm{MD}=-0.55, \quad 95 \% \quad \mathrm{CI} \quad(-1.57, \quad 0.47), \quad P=0.29$; Additional file 3: Figure S2], birth weight [MD $=-18.70$, 95\% CI $(-52.49,15.08), P=0.28$; Additional file 4: Figure S3], and the odds of caesarean section $[R R=$ $0.88,95 \%$ CI $(0.72,1.08), P=0.21$; Additional file 5: Figure S4].

\section{Discussion}

\section{Main findings}

This meta-analysis of eight studies that included 2981 pregnant women suggests that exercise during pregnancy has a significant protective impact on the occurrence of GDM, and decrease gestational weight gain. Exercise during pregnancy does not reduce the gestational age of 


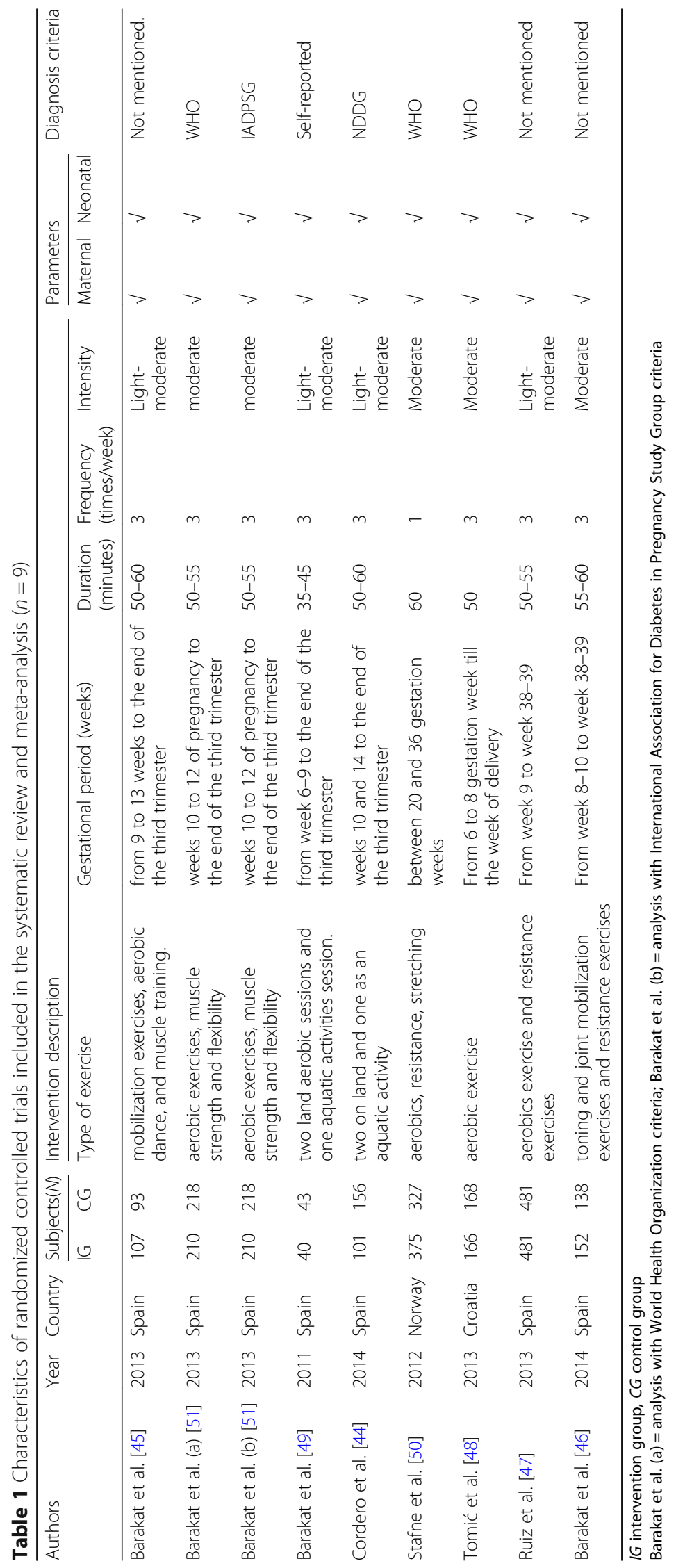




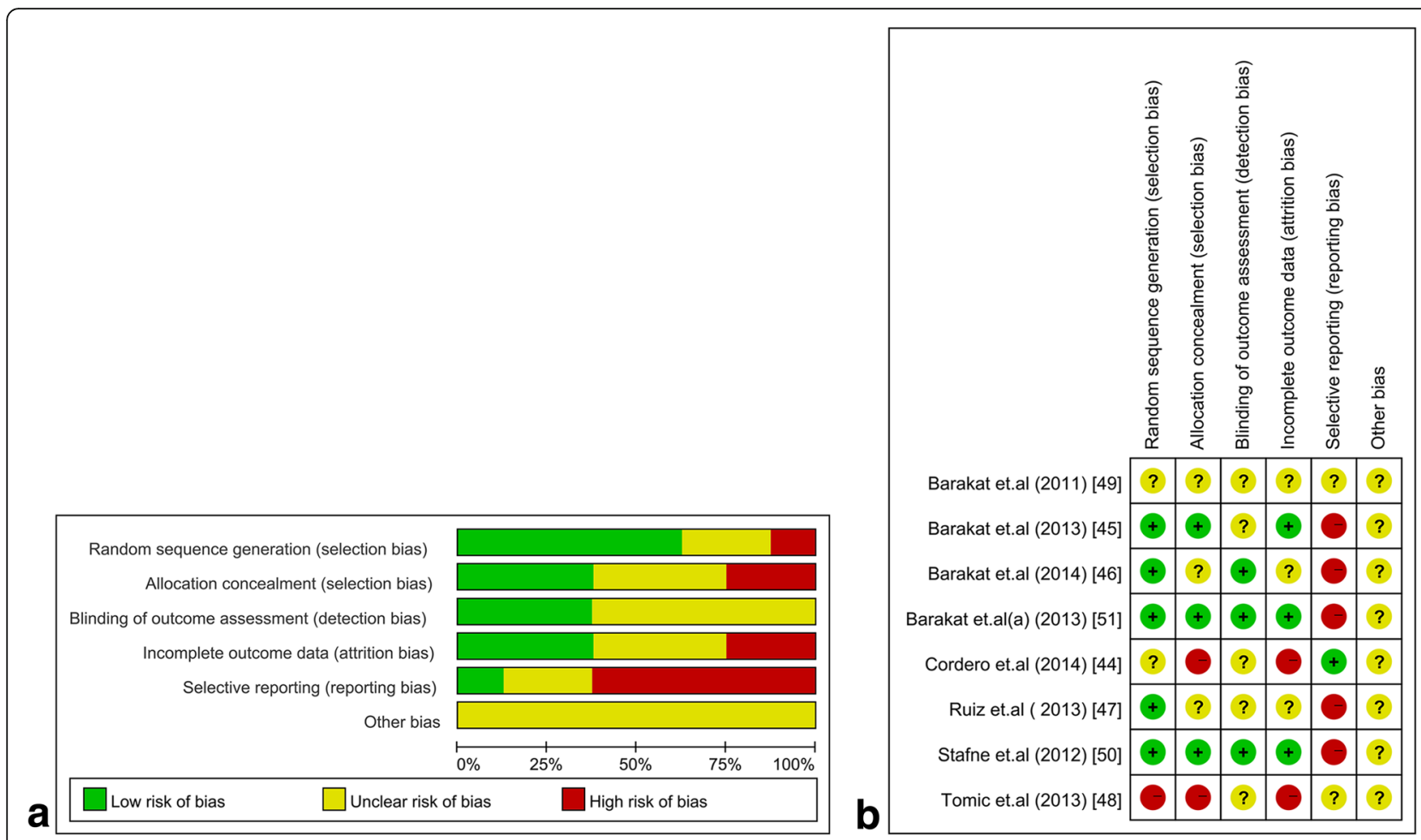

Fig. 3 Assessment of risk of bias. (a) Risk of bias graph about each risk of bias item presented as percentage across all included studies. (b) Summary of risk for bias for each trial; Plus sign: low risk of bias; minus sign: high risk of bias; question mark: unclear risk of bias

delivery or increase the odds of cesarean section in mostly normal-weight pregnant women. The mean gestational age at delivery, birth weight, and the odds of cesarean section are similar in women who exercise regularly and women who receive routine prenatal care. Summary of findings was shown in Additional file 6: Table S1.

\section{Comparisons with the existing literature}

Recently, Shepherd et al. described the effect of combined exercise and diet intervention on preventing
GDM in detail, and suggested that combined diet and exercise interventions can reduce risks of GDM [52]. The meta-analysis conducted by Sanabria-Martinez et al., which included all BMI categories, showed that structured exercise during pregnancy could prevent GDM and prevent excessive weight gain [28]. Another meta-analysis performed by Magro-Malosso et al. demonstrated that aerobic exercise during pregnancy, with or without dietary intervention, could reduce the incidence of GDM in overweight and obese women [27].

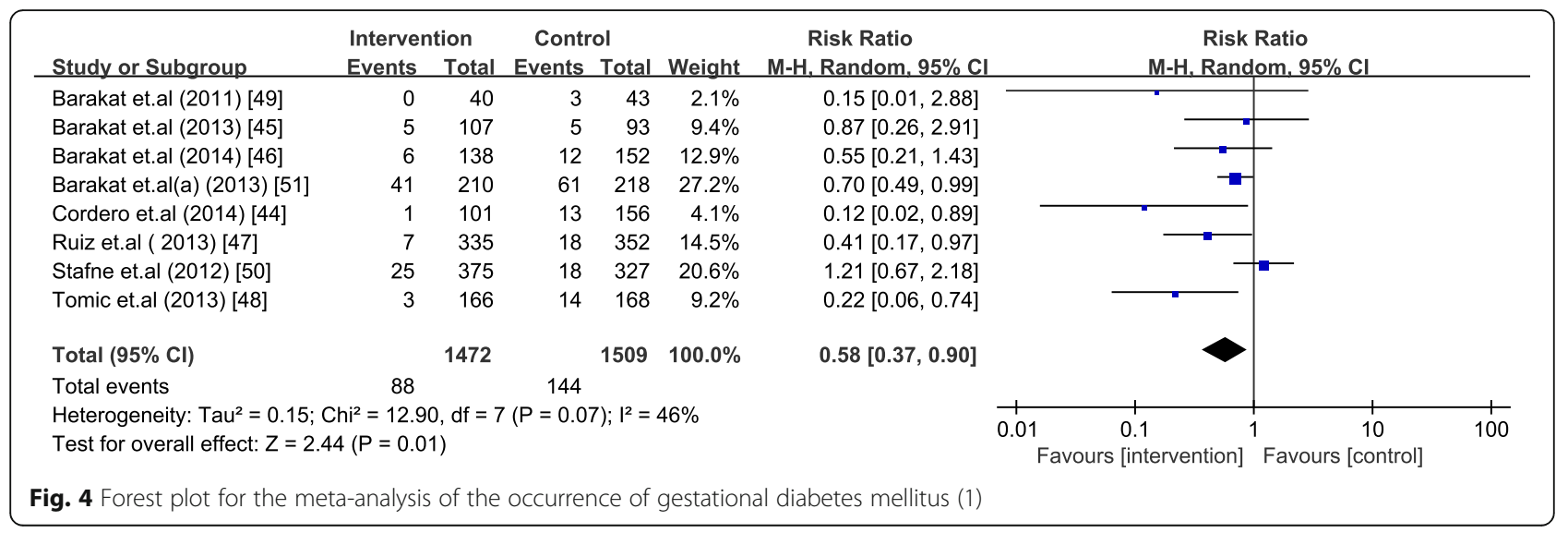




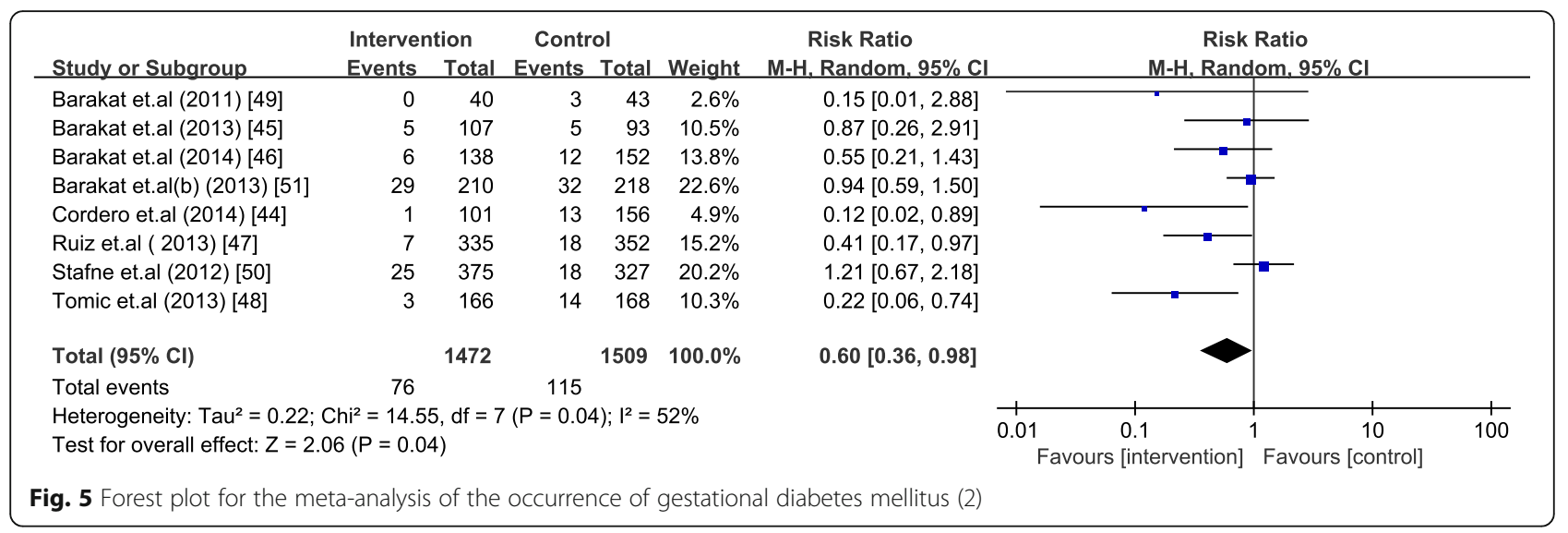

Recently, Di Mascio et al., in a meta-analysis of nine trials-including 2059 normal-weight women-showed that exercise during pregnancy was not associated with an increased risk of preterm birth. However, these authors found that exercise was correlated with a significantly lower incidence of GDM, cesarean delivery, and hypertensive disorders [29]. All of these studies support our findings. On the other hand, a meta-analysis conducted in 2014 suggested that physical exercise had no significant effect on lowering the occurrence of GDM. However, this study included only 947 pregnant women. In addition, exercise during pregnancy can also decrease the risk of gestational hypertension, preterm birth, cesarean delivery and macrosomia, which can significantly decrease the perinatal morbidity and mortality [53, 54].

\section{Strengths and limitations}

To the best of our knowledge, this study is the first meta-analysis focused on normal-weight women to examine the relationship between exercise/physical activity and the occurrence of GDM. This meta-analysis included all eight RCTs on the topic that have been published so far, with a larger sample size (2981 women) than earlier meta-analyses. Individual studies did not affect the overall results because of the similar sample size of each included study. These key factors are essential for assessing the validity of a meta-analysis.

However, our analysis has some limitations. The baseline characteristics (e.g., maternal age, occupation, educational level, household income, etc.) of the participants across the included studies were not balanced. Furthermore, compliance with the intervention and the effect of exercise might have varied due to differences in maternal education levels, parity, residence, and lifestyle habits before pregnancy; no included study reported adherence and compliance with the exercise regimens. Only one trial was stratified by pre-pregnancy BMI when assessing outcomes [47]; therefore, the mean BMI of the women included in all of the RCTs was in the normal range, but some of the studies might have included a small proportion of underweight, overweight, or obese women. The result of funnel plot suggested possible publication bias, which indicated the effect of exercise during pregnancy on decreasing the risks of GDM was likely reported in published studies, yielding over-estimation of the true effect. Moreover, the method for objectively monitoring physical activity is needed. Cordero et al. [44] used a heart rate monitor to modulate the intensity of exercise, but such set-up has not yet proofed as the best site for pregnant women.

\section{Conclusions and interpretation}

Over a decade, healthcare professionals have mainly focused on overweight/obese women's exercise during pregnancy related to GDM. However, there is a considerable proportion of GDM women having a normal pre-pregnancy BMI. Also, the majority group in the whole pregnancy population is those with normal pre-pregnancy BMI. From a cost-effectiveness perspective, we need to be more concerned about those women with a normal pre-pregnancy BMI. Our study shows light-to-moderate exercise for 30-60 min, three times a week, during pregnancy is safe and worthy of promotion in normal-weight women with uncomplicated, single pregnancies. This type of exercise could significantly decrease the occurrence of GDM and gestational weight gain, which is associated with adverse outcomes like gestational hypertension, preeclampsia. Besides, exercise during pregnancy is not associated with a reduction of mean gestational age at delivery or an increase in the odds of cesarean delivery. Therefore, our findings support the RCOG recommendations that women with uncomplicated pregnancies should engage in $30 \mathrm{~min}$ of moderate physical activity at least four times per week in all trimesters. Our finding indicates that the physical 
activity intervention in normal pre-BMI women could be a cost-effective or cost-saving management among the pregnancy population with normal pre-pregnancy BMI. Future studies should include larger cohorts to examine the association between exercise pattern (frequency and intensity) and glucose level, and to identify exercise amount and intensity that are suitable for the pregnancy population.

\section{Additional files}

Additional file 1: Textbox 1. Search terms used to identify articles related to exercise and gestational diabetes mellitus. (DOCX $12 \mathrm{~kb}$ )

Additional file 2: Figure S1. Forest plot for the meta-analysis of the gestational weight gain (kg). (PDF $400 \mathrm{~kb}$ )

Additional file3: Figure S2. Forest plot for the meta-analysis of the gestational age at birth (days). (PDF $514 \mathrm{~kb}$ )

Additional file 4: Figure S3. Forest plot for the meta-analysis of the birth weight (g). (PDF $593 \mathrm{~kb}$ )

Additional file 5: Figure S4. Forest plot for the meta-analysis of the odds of caesarean section. (PDF $438 \mathrm{~kb}$ )

Additional file 6: Table S1. Summary of findings. (PDF $88 \mathrm{~kb}$ )

\section{Abbreviations}

BMI: Body mass index; Cl: Confidence interval; CVD: Cardiovascular diseases: GDM: Gestational diabetes mellitus; GWG: Gestational weight gain; IADPSG: The International Association of Diabetes and Pregnancy Study Groups; NDDG: National Diabetes Data Group; OR: Odds risk; PRISMA: Preferred reporting items for systematic reviews and meta-analyses; RCOG: Royal College of Obstetricians and Gynecologists; RCT: Randomized controlled trials; SMD: Standard mean differences; T2DM: Type 2 diabetes mellitus; WHO: World Health Organization

\section{Acknowledgements}

No applicable.

\section{Funding}

No applicable.

\section{Availability of data and materials}

The datasets used and/or analysed during the current study are available from the corresponding author on reasonable request.

\section{Authors' contributions}

ZW contributed to discussion and reviewed and edited the manuscript. WM and WD designed the study, searched the published work, extracted articles, analysed data, and drafted the manuscript. CJPZ interpreted the data, and reviewed and edited the manuscript. LZ selected articles, extracted data, and commented on drafts. YL, ZL, CS, YW, HC1 and HC2 commented and edited the manuscript. HC2 would correspond to the author furthest up on the author list.

\section{Competing interest}

The authors declare that they have no competing interests.

\section{Ethics approval and consent to participate}

Not applicable.

\section{Consent for publication}

Not applicable.

\section{Publisher's Note}

Springer Nature remains neutral with regard to jurisdictional claims in published maps and institutional affiliations.

\section{Author details}

'Department of Obstetrics and Gynaecology, The First Affiliated Hospital of Sun Yat-sen University, Guangzhou, China. ${ }^{2}$ Harvard Medical School, Harvard University, Boston, MA, USA. ${ }^{3}$ Division of Pharmacoepidemiology and Pharmacoeconomics, Brigham and Women's Hospital, Boston, MA, USA. ${ }^{4}$ School of Public Health, The University of Hong Kong, Hong Kong, China.

Received: 7 April 2018 Accepted: 19 October 2018

Published online: 12 November 2018

\section{References}

1. Metzger BE, Lowe LP, Dyer AR, Trimble ER, Chaovarindr U, Coustan DR, et al. Hyperglycemia and adverse pregnancy outcomes. N Engl J Med. 2008; 358(19):1991-2002.

2. Organization, W.H., Diagnostic criteria and classification of Hyperglycaemia first detected in pregnancy. 2013.

3. Metzger BE, Gabbe SG, Persson B, Buchanan TA, Catalano PA, Damm P, et al. International association of diabetes and pregnancy study groups recommendations on the diagnosis and classification of hyperglycemia in pregnancy. Diabetes Care. 2010;33(3):676-82.

4. Sacks DA, Hadden DR, Maresh M, Deerochanawong C, Dyer AR, Metzger BE, et al. Frequency of gestational diabetes mellitus at collaborating centers based on IADPSG consensus panel-recommended criteria: the hyperglycemia and adverse pregnancy outcome (HAPO) study. Diabetes Care. 2012;35(3):526-8.

5. Chodick G, Elchalal U, Sella T, Heymann AD, Porath A, Kokia E, et al. The risk of overt diabetes mellitus among women with gestational diabetes: a population-based study. Diabet Med. 2010;27(7):779-85.

6. Getahun, D., M.J. Fassett and S.J. Jacobsen, Gestational diabetes: risk of recurrence in subsequent pregnancies. Am J Obstet Gynecol, 2010. 203(5): p. 467.e1-6.

7. Petry CJ. Gestational diabetes: risk factors and recent advances in its genetics and treatment. Br J Nutr. 2010;104(6):775-87.

8. Cypryk K, Szymczak W, Czupryniak L, Sobczak M, Lewinski A. Gestational diabetes mellitus - an analysis of risk factors. Endokrynol Pol. 2008;59(5):393-7.

9. O'Sullivan JB. Body weight and subsequent diabetes mellitus. JAMA. 1982; 248(8):949-52.

10. Bellamy L, Casas JP, Hingorani AD, Williams D. Type 2 diabetes mellitus after gestational diabetes: a systematic review and meta-analysis. Lancet. 2009;373(9677):1773-9.

11. Landon MB, Spong CY, Thom E, Carpenter MW, Ramin SM, Casey B, et al. A multicenter, randomized trial of treatment for mild gestational diabetes. $\mathrm{N}$ Engl J Med. 2009;361(14):1339-48.

12. Crowther CA, Hiller JE, Moss JR, McPhee AJ, Jeffries WS, Robinson JS. Effect of treatment of gestational diabetes mellitus on pregnancy outcomes. N Engl J Med. 2005;352(24):2477-86.

13. Wendland EM, Torloni MR, Falavigna M, Trujillo J, Dode MA, Campos MA, et al. Gestational diabetes and pregnancy outcomes--a systematic review of the World Health Organization (WHO) and the International Association of Diabetes in pregnancy study groups (IADPSG) diagnostic criteria. BMC Pregnancy Childbirth. 2012;12:23.

14. Ferrara A, Kahn HS, Quesenberry CP, Riley C, Hedderson MM. An increase in the incidence of gestational diabetes mellitus: northern California, 19912000. Obstet Gynecol. 2004;103(3):526-33.

15. Langer $\mathrm{O}$, Mazze R. The relationship between large-for-gestational-age infants and glycemic control in women with gestational diabetes. Am J Obstet Gynecol. 1988;159(6):1478-83.

16. Clausen TD, Mathiesen ER, Hansen T, Pedersen O, Jensen DM, Lauenborg J, et al. Overweight and the metabolic syndrome in adult offspring of women with diet-treated gestational diabetes mellitus or type 1 diabetes. J Clin Endocrinol Metab. 2009;94(7):2464-70.

17. Yogev Y, Visser GH. Obesity, gestational diabetes and pregnancy outcome. Semin Fetal Neonatal Med. 2009;14(2):77-84.

18. Ben-Haroush A, Yogev $Y$, Hod M. Epidemiology of gestational diabetes mellitus and its association with type 2 diabetes. Diabet Med. 2004; 21(2):103-13.

19. Clapp JF. Effects of diet and exercise on insulin resistance during pregnancy. Metab Syndr Relat Disord. 2006;4:84-90.

20. Organization, W.H., Global recommendations on physical activity for health. 2017. 
21. Sanabria-Martinez G, Garcia-Hermoso A, Poyatos-Leon R, Gonzalez-Garcia A, Sanchez-Lopez M, Martinez-Vizcaino V. Effects of exercise-based interventions on neonatal outcomes: a meta-analysis of randomized controlled trials. Am J Health Promot. 2016;30(4):214-23.

22. Colberg SR, Sigal RJ, Fernhall B, Regensteiner JG, Blissmer BJ, Rubin RR, et al. Exercise and type 2 diabetes: the American College of Sports Medicine and the American Diabetes Association: joint position statement executive summary. Diabetes Care. 2010;33(12):2692-6.

23. Hawley JA, Lessard SJ. Exercise training-induced improvements in insulin action. Acta Physiol (Oxf). 2008;192(1):127-35.

24. Royal College of Obstetricians and Gynaecologists. Exercise in Pregnancy. London: Statement No. 2006:4.

25. da Silva SG, Ricardo LI, Evenson KR, Hallal PC. Leisure-time physical activity in pregnancy and maternal-child health: a systematic review and metaanalysis of randomized controlled trials and cohort studies. Sports Med. 2017;47(2):295-317.

26. Yu Y, Xie R, Shen C, Shu L. Effect of exercise during pregnancy to prevent gestational diabetes mellitus: a systematic review and meta-analysis. J Matern Fetal Neonatal Med. 2017:1-6.

27. Magro-Malosso ER, Saccone G, Di Mascio D, Di Tommaso M, Berghella V. Exercise during pregnancy and risk of preterm birth in overweight and obese women: a systematic review and meta-analysis of randomized controlled trials. Acta Obstet Gynecol Scand. 2017:96(3):263-73.

28. Sanabria-Martinez G, Garcia-Hermoso A, Poyatos-Leon R, Alvarez-Bueno C, Sanchez-Lopez M, Martinez-Vizcaino V. Effectiveness of physical activity interventions on preventing gestational diabetes mellitus and excessive maternal weight gain: a meta-analysis. Bjog-An Int J Obstet Gynaecol. 2015;122(9):1167-74

29. Di Mascio D, Magro-Malosso ER, Saccone G, Marhefka GD, Berghella V. Exercise during pregnancy in normal-weight women and risk of preterm birth: a systematic review and meta-analysis of randomized controlled trials. Am J Obstet Gynecol. 2016;215(5):561-71.

30. Korpi-Hyovalti EA, Laaksonen DE, Schwab US, Vanhapiha TH, Vihla KR, Heinonen ST, et al. Feasibility of a lifestyle intervention in early pregnancy to prevent deterioration of glucose tolerance. BMC Public Health. 2011;11:179

31. Gray-Donald K, Robinson E, Collier A, David K, Renaud L, Rodrigues S. Intervening to reduce weight gain in pregnancy and gestational diabetes mellitus in Cree communities: an evaluation. CMAJ. 2000;163(10):1247-51.

32. Rakhshani A, Rakhshani A, Nagarathna R, Mhaskar R, Mhaskar A, Thomas A, Gunasheela $S$. The effects of yoga in prevention of pregnancy complications in high-risk pregnancies: a randomized controlled trial. Prev Med. 2012;55(4):333-40.

33. Hopkins SA, Baldi JC, Cutfield WS, McCowan L, Hofman PL. Exercise training in pregnancy reduces offspring size without changes in maternal insulin sensitivity. J Clin Endocrinol Metab. 2010;95(5):2080-8.

34. Korpi-Hyovalti E, Heinonen S, Schwab U, Laaksonen DE, Niskanen L. Effect of intensive counselling on physical activity in pregnant women at high risk for gestational diabetes mellitus. A clinical study in primary care. Prim Care Diabetes. 2012;6(4):261-8.

35. Nobles C, Marcus BH, EJRd S, Braun B, Whitcomb BW, Solomon CG, et al. Effect of an exercise intervention on gestational diabetes mellitus: a randomized controlled trial. Obstet Gynecol. 2015:125(5):1195-204.

36. Price BB, Amini SB, Kappeler K. Exercise in pregnancy: effect on fitness and obstetric outcomes-a randomized trial. Med Sci Sports Exerc. 2012;44(12):2263-9.

37. Shuang Wang JMHY. Lifestyle intervention for gestational diabetes mellitus prevention: A cluster-randomized controlled study. Chronic Diseases and Translational Medicine. 2015;1:169-74.

38. Sagedal LR, Overby NC, Bere E, Torstveit MK, Lohne-Seiler H, Smastuen M, et al. Lifestyle intervention to limit gestational weight gain: the Norwegian fit for delivery randomised controlled trial. BJOG. 2017;124(1):97-109.

39. Sagedal LR, Vistad I, Overby NC, Bere E, Torstveit MK, Lohne-Seiler H, et al. The effect of a prenatal lifestyle intervention on glucose metabolism: results of the Norwegian fit for delivery randomized controlled trial. BMC Pregnancy Childbirth. 2017;17(1):167.

40. Yeo S. A randomized comparative trial of the efficacy and safety of exercise during pregnancy: design and methods. Contemp Clin Trials. 2006;27(6):531-40.

41. White E, Pivarnik J, Pfeiffer K. Resistance training during pregnancy and perinatal outcomes. J Phys Act Health. 2014;11(6):1141-8.
42. Leng J, Liu G, Zhang C, Xin S, Chen F, Li B, et al. Physical activity, sedentary behaviors and risk of gestational diabetes mellitus: a population-based cross-sectional study in Tianjin, China. Eur J Endocrinol. 2016;174(6):763-73.

43. Morkrid K, Jenum AK, Berntsen S, Sletner L, Richardsen KR, Vangen S, et al. Objectively recorded physical activity and the association with gestational diabetes. Scand J Med Sci Sports. 2014;24(5):e389-97.

44. Cordero Y, Mottola MF, Vargas J, Blamco M, Barakat R. Exercise is associated with a reduction in gestational diabetes mellitus. Med Sci Sports Exerc. 2015;47(7):1328-33.

45. Barakat R, Perales M, Bacchi M, Coteron J, Refoyo I. A program of exercise throughout pregnancy. Is it safe to mother and newborn? Am J Health Promot. 2014;29(1):2-8.

46. Barakat R, Palaez M, Montejo R, Refoyo I, Coteron J. Exercise throughout pregnancy does not cause preterm delivery: a randomized, controlled trial. $J$ Phys Act Health. 2014;11(5):1012.

47. Ruiz JR, Perales M, Pelaez M, Lopez C, Lucia A, Barakat R. Supervised exercise-based intervention to prevent excessive gestational weight gain: a randomized controlled trial. Mayo Clin Proc. 2013;88(12):1388-97.

48. Tomic V, Sporis G, Tomic J, Milanovic Z, Zigmundovac-Klaic D, Pantelic C. The effect of maternal exercise during pregnancy on abnormal fetal growth Croat Med J. 2013;54(4):362-8.

49. Barakat R, Cordero Y, Coteron J, Luaces M, Montejo R. Exercise during pregnancy improves maternal glucose screen at 24-28 weeks: a randomised controlled trial. Br J Sports Med. 2012;46(9):656-61.

50. Stafne SN, Salvesen KA, Romundstad PR, Eggebo TM, Caelsen SM, Morkved S. Regular exercise during pregnancy to prevent gestational diabetes: a randomized controlled trial. Obstet Gynecol. 2012;119(1):29-36.

51. Barakat R, Pelaez M, Lopez C, Lucia A, Ruiz JR. Exercise during pregnancy and gestational diabetes-related adverse effects: a randomised controlled trial. Br J Sports Med. 2013;47(10):630-6.

52. Shepherd R., Gomersall J.C., Tieu J., Han S., Crowther C.A., Middleton P. Combined diet and exercise interventions for preventing gestational diabetes mellitus (Review). Cochrane Database of Systematic Reviews 2017, Issue 11. Art. No.: CD010443.

53. Magro-Malosso ER, Saccone G, Di Tommaso M, Roman A, Berghella V. Exercise during pregnancy and risk of gestational hypertensive disorders: a systematic review and meta-analysis. Acta Obstet Gynecol Scand. 2017;96(8):921-31.

54. Berghella V, Saccone G. Exercise in pregnancy. Am J Obstet Gynecol. 2017s; 216(4):335-7.
Ready to submit your research? Choose BMC and benefit from:

- fast, convenient online submission

- thorough peer review by experienced researchers in your field

- rapid publication on acceptance

- support for research data, including large and complex data types

- gold Open Access which fosters wider collaboration and increased citations

- maximum visibility for your research: over $100 \mathrm{M}$ website views per year

At $\mathrm{BMC}$, research is always in progress.

Learn more biomedcentral.com/submissions 